\title{
A Qualitative Seminested PCR Assay as an Alternative to Urine Cytology for BK Polyomavirus Screening after Renal Transplantation
}

\author{
Ana Carolina Jonard Zalona ${ }^{a}$ Rafael Brandão Varella ${ }^{d} \quad$ Cristina Maeda Takiyac \\ Renato Torres Goncalves ${ }^{b}$ Mariano Gustavo Zalis ${ }^{a} \quad$ Guilherme Santoro-Lopes ${ }^{a}$ \\ ${ }^{a}$ Department of Preventive Medicine, Faculdade de Medicina, ${ }^{b}$ Nephrology Unit, Hospital Universitário Clementino \\ Fraga Filho and 'Instituto de Biofísica Carlos Chagas Filho, Universidade Federal do Rio de Janeiro, ${ }^{\mathrm{d}}$ Department of \\ Microbiology and Parasitology, Universidade Federal Fluminense, Rio de Janeiro, Brazil
}

\section{Key Words}

BK polyomavirus $\cdot$ Seminested PCR · Decoy cell .

Polyomavirus-associated nephropathy

\begin{abstract}
Objective: Polyomavirus-associated nephropathy (PVAN) is a major cause of graft dysfunction after kidney transplantation. Therefore, routine screening for BK polyomavirus (BKV) infection with urine cytology or quantitative PCRbased assays has been recommended. Although less expensive than quantitative tests, qualitative PCR assays are not recommended for screening based on the assumption that their diagnostic accuracy is inferior to urine cytology. However, studies comparing the performance of both methods are scarce. Methods: We compared the accuracy between a qualitative seminested PCR (snPCR) assay and urine cytology for the screening of BKV viruria in 104 renal transplant recipients. Results: The snPCR assay was more sensitive than cytology (100 and $61 \%$, respectively), yielding better negative predictive value (100 vs. 90\%). In 7 (39\%) of the 18 PVAN cases, BKV infection was detected exclusively by snPCR. Although the specificity of snPCR (63\%) was lower than cytology $(74 \%)$, their positive predictive values were similar ( 36 vs. $33 \%$, respectively). In ROC curve analysis, the accuracy of snPCR was significantly higher
\end{abstract}

$(p=0.03)$. Conclusion: This qualitative snPCR assay was more accurate than urine cytology for the detection of BKV viruria in renal transplant patients.

Copyright $\odot 2013$ S. Karger AG, Basel

BK polyomavirus (BKV) was first described in 1970 by Gardner and colleagues, but only in the mid-1990s was the virus related to opportunistic nephropathy in renal allograft recipients $[1,2]$. In immunocompetent individuals, the virus remains latent in uroepithelial and renal tubular cells and reactivates in a minority of subjects without clinical relevance [3]. However, after renal transplantation, polyomavirus-associated nephropathy (PVAN) evolves in 1-10\% of the patients [4], resulting in allograft loss in up to $80 \%$ of cases and is, therefore, considered an emerging disease in transplantation [5].

Early detection of BKV in urine and/or blood samples $[6,7]$ is an essential component of the recommended strategy to prevent graft loss by PVAN, as it may allow for timely reduction of immunosuppressive therapy, avoiding graft loss $[4,8]$. According to current recommendations $[6,7]$, regular urine screening after renal transplantation should be performed preferably by quantitative PCR [7]. Urine cytology (decoy cell) is considered an alternative low-cost method that presents good correlation

\section{KARGER}

E-Mail karger@karger.com

www.karger.com/int (c) 2013 S. Karger AG, Basel

0300-5526/13/0564-0249\$38.00/0 
Table 1. Comparison of snPCR versus cytology (decoy cells) screening tests for BKV viruria in kidney transplant recipients $(\mathrm{n}=104)$

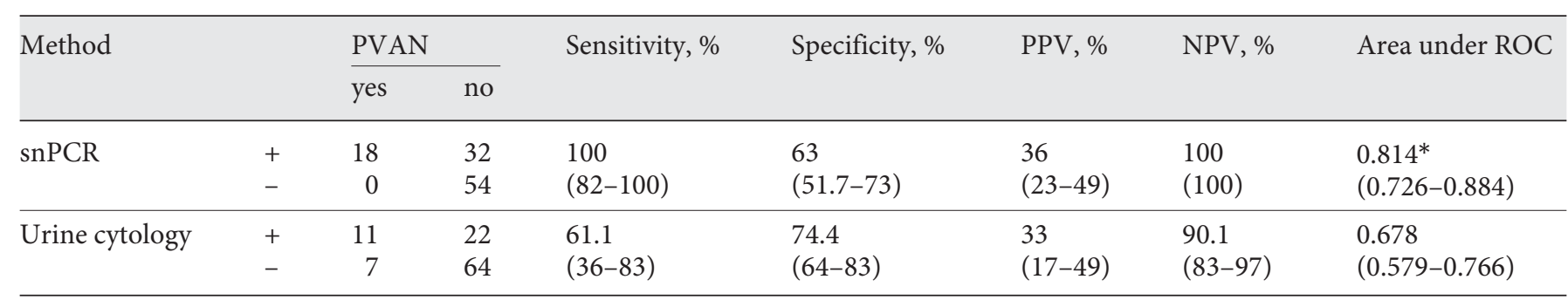

95\% confidence intervals are given in parentheses. $\mathrm{PPV}=$ positive predictive value; $\mathrm{NPV}=$ negative predictive value; $\mathrm{ROC}=$ receiver-operator curve. ${ }^{*} \mathrm{p}=0.03$.

with quantitative PCR assays despite its lower negative predictive value for BKV nephropathy $[9,10]$. Qualitative PCR assays, although less expensive than quantitative tests, are not recommended as a screening method based on the assumption that their lower specificity would increase the number of patients unnecessarily submitted to further diagnostic tests [3]. However, studies comparing the performance of qualitative PCR assays with other screening tests for BKV viruria are scarce.

In a previous study designed to assess the prevalence of BKV subtypes among renal transplant recipients in Brazil, we developed a qualitative seminested PCR (snPCR) assay to detect BKV in urine samples [11]. In the present report, we analyzed follow-up data to compare the accuracy of snPCR and urine cytology as an initial screening method to detect patients at risk of developing PVAN. This study was approved by the Institutional Committee on Research Ethics (protocol 062/07).

Patients submitted to kidney transplantation between 2005 and 2009 were included in the study after providing written informed consent, and followed up to December 2010. From each patient, 5-ml urine samples were collected in a sterile vessel and centrifuged at $287 \mathrm{~g}$ for $15 \mathrm{~min}$. Urine supernatants were discarded and the cell pellets were both used for cytology and PCR. Urine cytology for decoy cell identification was performed with a standard Papanicolaou stain. For snPCR, each urine sample was submitted to DNA extraction using a Wizard $^{\mathrm{TM}}$ Genomic DNA Purification kit (Promega, Madison, Wisc., USA) according to the manufacturer's instructions. snPCR targeting a conserved region of BKV VP1 was performed as described previously [11].

The diagnosis of PVAN was defined by the detection of positive immunohistochemical nuclear staining with the anti-BKV large T antigen monoclonal antibody [7] in cases that presented typical viral cytopathic changes in the epithelial cells of tubules, glomeruli or collecting ducts, with or without typical viral nuclear inclusions in hematoxylin eosin-stained sections. Histological patterns were defined according to the consensus conference on PVAN [5].

Sensitivity, specificity and negative and positive predictive values for the prediction of PVAN were calculated for both methods. ROC curve analysis was performed to compare the accuracy of urine cytology and snPCR. The comparison of the area under the ROC curves built for each method was performed with the DeLong test (1988) [12] using Medcalc software (Mariakerke, Belgium).

One hundred and four patients were included in the study and screened for BKV after a median 7 months (interquartile range, IQR, 2-14 months) following transplantation. Their median serum creatinine level at the time of urine sample collection was $1.3 \mathrm{mg} / \mathrm{dl}$ (IQR 1.2$1.9 \mathrm{mg} / \mathrm{dl}$ ). BKV viruria was detected by urine cytology in 33 patients (32\%) and by snPCR in 50 subjects (48\%). snPCR was positive for all patients who had decoy cells detected in the urine.

Eighteen (17\%) of the 104 patients included in the study had a follow-up diagnosis of PVAN. According to the histopathologic classification of PVAN, 5 patients were stage $A, 12$ were stage $B$ and 1 was stage $C$. The anal$y$ sis of performance of the urinary screening tests to predict the occurrence of the nephropathy is summarized in table 1. Overall, snPCR was considerably more sensitive than cytology, with a higher negative predictive value. Although the specificity of snPCR was lower compared with urine cytology, both tests had similar positive predictive values. In ROC curve analysis, the accuracy of snPCR was significantly higher $(\mathrm{p}=0.03)$. Of the 7 patients $(39 \%)$ who were exclusively detected by snPCR, 6 had a renal histological classification score of PVAN B and 1 scored as PVAN A. 
These results suggest that the qualitative snPCR developed in this study is significantly more accurate than urine cytology to detect patients at risk for PVAN. snPCR was substantially more sensitive than decoy cell cytology, while its specificity was moderately lower. Because of their lower specificity, qualitative PCR assays have been regarded as unsuitable as a screening method for BKV viruria because of the assumption that their use would lead to an unnecessary increase in the use of further diagnostic tests. The finding that snPCR and urine cytology had similar positive predictive values in this study does not support that assumption and indicates that this qualitative PCR assay may be a useful alternative to screen for BKV infection among renal transplant recipients. Accordingly, Montagner et al. [13] observed that a similar PCR assay was a more sensitive predictor of BKV viremia than urine cytology.

It could be argued that cytology is cost saving, easier to perform and can be performed in any modest routine laboratory without cross-contamination risks. However, cytology results are more susceptible to delays in processing and shipment of samples [5]. The resulting lower sensitivity may delay the recognition of active BKV infection, which may have a negative impact on graft survival in a considerable proportion of affected patients. In fact, the snPCR assay analyzed in this study showed a higher negative predictive value. Although more costly than urine cytology, it is considerably less expensive than quantitative PCR methodologies, such as real-time PCR, for BKV screening in urine samples. Therefore, we believe that this qualitative snPCR assay might help to improve the quality of care of renal transplant recipients in many centers, especially those located in developing countries, where the routine use of quantitative PCR assays as a screening tool still cannot be afforded. Indeed, the results of two previous studies further support the clinical utility of qualitative PCR assays, both in urine and blood, to predict patients at risk of PVAN $[14,15]$. However, in both studies, the diagnostic performance of the qualitative PCR assay used was not compared to any other test.

The 32\% prevalence of detection of decoy cells found in this study is within the range of 16.9 to $37.5 \%$ reported in other Brazilian studies [16-19]. Few Brazilian studies used molecular assays to determine the prevalence of BKV infection among transplant recipients $[13,20]$. Montagner et al. [13], using another qualitative snPCR assay, reported prevalences of 62 and $43 \%$ for viruria and viremia, respectively, in a sample of selected renal transplant patients who presented graft dysfunction. Among unselected renal transplant recipients, Pires et al. [20], using a standard qualitative PCR assay, reported viruria in $30.5 \%$ of the patients, a prevalence considerably lower than the $48.5 \%$ found in the present study. It is possible, to some extent, that such difference may have been partially influenced by characteristics of the PCR assays used in both studies. Urea is a potential PCR inhibitor in urine samples [20,21] that may induce false-negative results. However, the use of a seminested technique, employing a high number of cycles, may mitigate this limitation and reduce the number of false negatives. In fact, in the present study, decoy cells were not found among patients with negative snPCR.

This study has some limitations. It has a cross-sectional design, and therefore urine samples were not collected at predetermined intervals after transplantation. It is possible that with serial sampling, the difference in the accuracy between snPCR and cytology might disappear, although this hypothesis requires testing.

The establishment of cost-effective and accurate screening protocols for BKV detection in urine samples is still under debate. In this study, a qualitative snPCR assay was more accurate than urine cytology for the detection of BKV viruria in renal transplant patients. Further studies, however, are needed to confirm the clinical usefulness of this snPCR assay for BKV screening.

\section{References}

1 Fioriti D, Degener AM, Mischitelli M, Videtta M, Arancio A, Sica S, Sora F, Pietropaolo $\mathrm{V}$ : BKV infection and hemorrhagic cystitis after allogeneic bone marrow transplant. Int J Immunopathol Pharmacol 2005; 18:309316.

2 Hirsch HH, Knowles W, Dickenmann M, Passweg J, Klimkait T, Mihatsch MJ, Steiger J: Prospective study of polyomavirus type BK replication and nephropathy in renal-transplant recipients. N Engl J Med 2002;347:488496.
3 Dharnidharka VR, Abdulnour HA, Araya CE: The BK virus in renal transplant recipients review of pathogenesis, diagnosis, and treatment. Pediatr Nephrol 2011;26:1763-1774.

4 Renoult E, Coutlée F, Pâquet M, St Louis G, Girardin C, Fortin MC, Cardinal H, Lévesque R, Schürch W, Latour M, Barama A, Hébert MJ: Evaluation of a preemptive strategy for BK polyomavirus-associated nephropathy based on prospective monitoring of BK viremia: a kidney transplantation center experience. Transplant Proc 2010;42:4083-4087.
5 Hirsch HH, Brennan DC, Drachenberg CB, Ginevri F, Gordon J, Limaye AP, Mihatsch MJ, Nickeleit V, Ramos E, Randhawa P, Shapiro R, Steiger J, Suthanthiran M, Trofe $\mathrm{J}$ : Polyomavirus-associated nephropathy in renal transplantation: interdisciplinary analyses and recommendations. Transplantation 2005;79:1277-1286.

6 Hirsch HH, Randhawa P, AST Infectious Diseases Community of Practice: BK virus in solid organ transplant recipients. Am J Transplant 2009;9:S136-S146. 
7 Kidney Disease: Improving Global Outcomes (KDIGO) Transplant Work Group: KDIGO clinical practice guideline for the care of kidney transplant recipients. Am J Transplant 2009;9(suppl 3):S1-S157.

8 Drachenberg CB, Papadimitriou JC, Ramos E: Histologic versus molecular diagnosis of BK polyomavirus-associated nephropathy: a shifting paradigm? Clin J Am Soc Nephrol 2006;1:374-379.

9 Drachenberg C, Hirsch HH, Papadimitriou JC, Mozafari P, Wali R, McKinney JD, Nogueira J, Cangro CB, Mendley S, Klassen DK, Ramos E: Cost efficiency in the prospective diagnosis and follow-up of polyomavirus allograft nephropathy. Transplant Proc 2004;36:3028-3031.

10 Lee KW, Lee HH, Lee DS, Kim SJ, Joh JW, Oh HY, Kim JW, Kim YG, Huh WS, Kim DJ, Lee SK, Lee BB: Polymerase chain reaction for the diagnosis of human polyomavirus-associated nephropathy in renal transplant recipients. Transplant Proc 2004;36:2116-2117.

11 Zalona ACJ, Santoro-Lopes G, Schrago CG Gonçalves RT, Zalis MG, Varella RB: Molecular Characterization of BK Polyomavirus Subtypes in Renal Transplant Recipients in Brazil. J Med Virol 2011;83:1401-1405.
12 DeLong E, DeLong D, Clark-Pearson D: Comparing the areas under two or more correlated receiver operating curves: a nonparametric approach. Biometrics 1988;44:837845.

13 Montagner J, Michelon T, Fontanelle B, Oliveira A, Silveira J, Schroeder R, Neumann J, Keitel E, Alexandre CO: BKV-infection in kidney graft dysfunction. Braz J Infect Dis 2010;14:170-174.

14 Wu SW, Chang HR, Hsieh MC, Chiou HL, Lin CC, Lian JD: Early diagnosis of polyomavirus type $\mathrm{BK}$ infection in tailoring immunosuppression for kidney transplant patients: screening with urine qualitative polymerase chain reaction assay. Transplant Proc 2008; 40:2389-2391.

15 Cross NB, Webster AC, O’Connell PJ, Jeoffreys N, Dwyer DE, Craig JC: Diagnostic accuracy of blood qualitative nucleic acid testing for polyomavirus-associated nephropathy in kidney recipients. Nephrology 2009;14: 350-356.

16 Kroth LV, Henkin CS, Peres LD, Paganella MC, Mazzali M, Duval VD, Traesel MA, Saitovitch D: Prevalence of urinary decoy cells and associated risk factors in a Brazilian kidney, pancreas, and kidney-pancreas transplant population. Transplant Proc 2012;44: 2394-2396.
17 Santos RL, Manfrinatto JA, Cia EM, Carvalho RB, Quadros KR, Alves-Filho G, Mazzali M: Urine cytology as a screening method for polyoma virus active infection. Transplant Proc 2004;36:899-901.

18 Ranzi AD, Prolla JC, Keitel E, Brackmann R, Kist R, dos Santos G, Bica CG: The role of urine cytology for 'decoy cells' as a screening tool in renal transplant recipients. Acta Cytol 2012;56:543-547.

19 Maia TM, Silva SF, Silva SL, Holanda MC, Nascimento JM, Ferreira MV: Polyomavirusinfected decoy cells in cytocentrifuged urine cytology specimens from renal transplant recipients. Acta Cytol 2011;55:445-448.

20 Pires EP, Bernardino-Vallinoto CV, Alves DM, Migone SR, Machado LF, Ishak MO, Ishak R, Cayres-Vallinoto IM, Vallinoto AC: Prevalence of infection by JC and BK polyomaviruses in kidney transplant recipients and patients with chronic renal disease. Transpl Infect Dis 2011;13:633-637.

21 Khan G, Kangro HO, Coates PJ, Heath RB: Inhibitory effects of urine on the polymerase chain reaction for cytomegalovirus DNA. J Clin Pathol 1991;44:360-366. 